\title{
DECONSTRUCTING THE INDUSTRIAL EMISSIONS DIRECTIVE's (2010/75/EU) REGULATORY STANDARDS: A TAle OF CAUTIOUS OPTIMISM
}

\author{
Aliki Zeri*
}

\begin{abstract}
Environmental policy has always been at the core of the EU's activities. In 2010, the EU adopted the Industrial Emissions Directive ('IED'). The IED considerably reformed the regulatory framework in this field and aimed to address concerns based on the lack of flexibility in EU governance. This contribution reviews the main characteristics of the IED's second chapter, concerning integrated pollution prevention and control ('IPPC') and assesses their relevance to notions of centralisation or "legalism" as contrasted to de-centralisation and flexibility. It argues that even though the Directive makes some progress towards the right direction, a number of thorny issues still remain unresolved.
\end{abstract}

\section{A. INTRODUCTION}

The regulation of industrial pollution has always been at the centre of the European Union's environmental policy. Influenced by the predominant regulatory model of the 1970s (the "command and control"1 or "direct regulation" $"$ model) the early phase of community legislation in this field exhibited two key characteristics: it was premised upon a permitting system and it was media-specific. ${ }^{3}$ In broad brushstrokes, within national regulatory frameworks the traditional regulatory tool of a license or permit 'commanded' compliance with a particular environmental target or methodology. ${ }^{4}$ Compliance was then 'controlled' through the imposition of sanctions. ${ }^{5}$ The subsequent embracement of this regulatory structure by the European Union implied, as Lee argues, "both command from the centre to the Member State and its regulators, and command and control of polluters". 6

\footnotetext{
*Aliki has an LLB and an LLM in Environmental Law and Policy. She is currently employed as an environmental paralegal in Bond Dickinson LLP. The author is grateful to M. Lee for all her support and assistance in the preparation of this paper. The author remains at your disposal for any queries or comments at: aliki.zeri@ucl.ac.uk

${ }^{1}$ Richard B.Macrory, Regulation, Enforcement and Governance in Environmental Law (Hart Publishing 2010) chapter 3.

2 ibid.

${ }^{3}$ Maria Lee, Draft paper, Blackwell Companion to EU Law and International Law (2012), 1.

${ }^{4}$ ibid.

${ }^{5}$ Macrory (n1).

${ }^{6}$ Lee (n 3).
} 
Nevertheless, during the late 1980s and early 1990s this prevalent model of 'command and control' regulation came under considerable criticism. ${ }^{7}$ In the European Union this criticism, compounded with powerful pressures towards de-centralisation resulted in the adoption of novel forms of environmental governance. Contrary to the USA, where the pertinent criticism originated $^{8}$, the European Union legislature did not opt for a generalised use of economic instruments; the European Union's Emissions Trading Scheme ${ }^{9}$ being a prominent exception. ${ }^{10}$ Instead the European Union sanctioned a hybrid regulatory approach exhibiting characteristics of both the "old governance" 11 of the 1970s and the "new governance" 12 structures, which emerged during the 1990s. The latter were premised upon mechanisms, which promoted, inter alia, flexibility, reflection and cooperation "over fixed hierarchical commands". ${ }^{13}$ The outcome of this novel "new, old governance" ${ }^{14}$ approach was community legislation which provided Member States with the necessary flexibility in its implementation, without simultaneously "engaging in outright de-centralisation". ${ }^{15}$ However, the novelty of the regulatory framework is not only related to the partial shift from centralised to de-centralised forms of governance in the European Union's environmental edifice. A second significant characteristic of this period is the movement away from media-specific and towards integrated pollution regulation. ${ }^{16}$

This novel regulatory approach was subsequently crystallised in the field of industrial pollution control in Directive 96/61/EC on integrated

\footnotetext{
7 Neil Gunningham, 'Environment Law, Regulation and Governance: Shifting Architectures' (2009) 21:2 Journal of Environment Law 179.

${ }^{8}$ Bruce A Ackerman and Richard B.Stewart, 'Reforming Environmental Law: The Democratic Case for Market Incentives' (1985) 13 Columbia Journal of Environmental Law 171.

${ }^{9}$ Directive 2009/29/EC amending Directive 2003/87/EC so as to improve and extend the greenhouse gas emission allowance trading scheme of the Community [2009] OJ L $140 / 63$.

${ }^{10}$ Lee (n 3).

11 Joanne Scott and David Trubek, 'Mind the Gap: Law and New Approaches to Governance in the EU' (2002) 8 ELJ 1.

12 ibid.

${ }^{13}$ Lee (n3).

${ }^{14}$ Scott, Trubek (n11).

${ }^{15}$ Maria Lee, EU Environmental Law-Challenges, change and decision-making (Hart Publishing 2005) 163.

${ }^{16}$ Michael G Faure and Jürgen GJ Lefevere, 'IPPC: An Economic Perspective' (1996) European Environmental Law Review 112.
} 
pollution prevention and control ${ }^{17}$ (IPPCD). The Directive, which entered into force in 1999, presents three innovative characteristics, which distinguish it from earlier legislation in the field. To begin with, Gislev was keen to highlight the Directive's emphasis on pollution prevention as opposed to earlier initiatives, which traditionally promoted "end-of-pipe pollution abatement measures". ${ }^{18}$ Furthermore, the IPPCD exhibits the two aforementioned characteristics of the second environmental governance period of the European Union; an integrated approach to pollution control and flexibility in implementation. ${ }^{19}$ Accordingly the Directive's envisaged flexibility was facilitated through the establishment of a permitting system, within which the regulation of pollution is primarily instituted through inherently flexible 'performance-based standards ${ }^{20}$ These take the form of 'emission limit values' (ELVs), which are to be set by the individual Member States in accordance with a "process-based standard"21; the 'BAT' (Best Available Techniques) standard. ${ }^{22}$ The "open-ended" 23 character of this standard vests Member States with considerable discretion in its determination. More importantly, this discretion operates on the backdrop of an "autonomous standard setting process" 24 (known as the "Sevilla process $"$ "25), within which both Member States and their regulated industries hold a prominent position.

Within the EU's diverse regulatory mosaic, the adoption of flexible forms of governance was perceived as crucial in ensuring the implementation of its demanding environmental legislation. ${ }^{26}$ Nevertheless,

\footnotetext{
${ }^{17}$ Directive 96/61/EC concerning integrated pollution prevention and control [1996] OJ L 257 (IPPCD).

${ }^{18}$ Magnus Gislev, 'European Innovation and Exchange of Information about BAT', paper presented at the European Conference on "The Sevilla Process: A Driver for Environmental Performance in Industry" (Stuttgart, 6 - 7 April 2000) 1, available at http://www.ecologic-events.eu/sevilla1/en/documents/Gislev_en.PDF

${ }^{19}$ Maria Lee and Jane Holder, Environmental Protection, Law and Policy $\left(2^{\text {nd }}\right.$ edn, CUP 2007), ch 9.

${ }^{20}$ On different types of standards, see Gertrude Lübbe-Wolf, 'Efficient Environmental Legislation-On Different Philosophies of Pollution Control in Europe' (2001) 13:1 Journal of Environmental Law 79.

${ }^{21}$ Stuart Bell and David McGillivray, Environmental Law (OUP 2008), 500.

${ }^{22}$ Article 9(4) IPPCD.

${ }^{23}$ Lee (n 3), 25.

${ }^{24}$ Maria Lee, 'Law and Governance of Water Protection Policy' in Joanne Scott (ed) Environmental Protection (OUP 2009) ch 2.

${ }^{25}$ On the 'Sevilla process', see Harald Schoenberger, 'Integrated pollution prevention and control in large industrial installations on the basis of best available techniques - The Sevilla Process' (2009) 17:16 Journal of Cleaner Production 1526.

${ }^{26}$ Lee (n15), ch 6.
} 
successive Commission reports on the implementation of the IPPCD appeared to challenge this presumption. ${ }^{27}$ Accordingly, the Commission's vision to address the Directive's "implementation gap" ${ }^{28}$ was promoted through the adoption of a new "framework directive on industrial emissions" ${ }^{29}$; the Industrial Emissions Directive (IED). ${ }^{30}$ The Directive, which recast the IPPCD and six other sectoral Directives into a single legislative act, is divided into seven chapters. Notwithstanding the significant issues raised by all of them, only the second chapter, which contains "the core of the old IPPC Directive",31, is discussed at this paper.

Even though the Directive retains the fundamental principles of the IPPCD-the principle of integration and the 'BAT' principle-intact, it appears, at least on the face of it, as being more centralised than its predecessor. ${ }^{32}$ According to Lee, some may view this Directive as signifying "the death of new governance". ${ }^{33}$ In the same vein, it is unarguably true that the IED brought about a number of changes aimed at enhancing the legal status of the 'BAT' standard. ${ }^{34}$ Nevertheless as it will be subsequently argued, these changes were in fact only incremental in character. ${ }^{35}$ This assumption is particularly significant for two reasons. To begin with, it refutes the initial misconception of the more centralised character of the Directive. Similarly to its predecessor, the IED appears to exhibit characteristics that could fit in with both a centralised and a decentralised account of the EU's environmental regulation. ${ }^{36}$ Moreover, the incremental character of the changes employed by the Directive poses interesting questions about its effectiveness. Indeed, a number of academics have

${ }^{27}$ For the latest report, see Commission, Report from the Commission on the implementation of Directive 2008/1/EC concerning integrated pollution prevention $\operatorname{COM}(2010) 593$ final.

${ }^{28}$ On the 'implementation gap' in the European Union's environmental law, see Lee (n 15) ch 3.

${ }^{29}$ Ludwig Kramer, EU Environmental Law (Sweet and Maxwell 2011), 163.

${ }^{30}$ Directive 2010/75/EU on industrial emissions OJ 2010 L 334/17 (IED).

${ }^{31}$ Bettina.Lange, 'The EU Directive on Industrial Emissions: Squaring the Circle of Integrated, Harmonised and Ambitious Technology Standards?' (2011) 13 Environmental Law Review 169.

${ }^{32}$ Lee (n 3), 3.

${ }^{33}$ ibid.

${ }^{34}$ Commission, Proposal for a Directive of the European Parliament and of the Council on industrial emissions (integrated pollution prevention and control) $\operatorname{COM(2007)~} 844$ final.

${ }^{35}$ Andrew Farmer, 'Revising IPPC: Incremental Change Rather than a Radical Overhaul of EU Industrial Emissions Policy’ (2008) 10:4 Environmental Law Review 258.

${ }^{36}$ Lee (n 3), 3. 
expressed concerns regarding the potential of the new IED to overcome the previously observed implementation problems and ultimately achieve its ambitious goal; "a high level of protection of the environment taken as a whole". ${ }^{37}$ It could therefore be maintained that the IED is indeed capable of narrating a tale of optimism, albeit one shadowed by considerable caution.

In light of the above, this paper, which draws on the work of Lee, will succinctly review the main characteristics of the IED and their relevance to notions of centralisation or "legalism" $" 38$ as contrasted to de-centralisation and flexibility. On the backdrop of the 'implementation gap' already identified under the previous regime, the potential of the mechanisms employed by the IED to address it will be subsequently assessed. A tentative conclusion will then be drawn that even though some progress towards the right direction has already been made, a number of thorny issues still remain unresolved.

\section{B. PART I: DEBATING SUBSTANCE AND PROCEDURE UNDER THE INDUSTRIAL EMISSIONS DIRECTIVE}

\section{THE DIRECTIVE'S SUBSTANTIVE ASPECTS}

Similarly to its predecessor the IED utilises a conventional 'command and control' instrument for the regulation of industrial pollution; the IPPC permit. ${ }^{39}$ In line with the Directive's integration principle, this regulatory instrument aims at ensuring both the necessary administrative and substantive integration. ${ }^{40}$ As far as administrative integration is concerned, the Directive requires only the full co-ordination of different agencies in granting the permit and not the establishment of a single permitting agency. ${ }^{41}$ This minimum form of integration, clearly illustrates the Directive's deference to the regulatory traditions of the diverse Member States. $^{42}$

Subsequently substantive integration is promoted through an array of regulatory standards, which should be incorporated into individual IPPC permits. Based on the traditional taxonomy of standards, the standards employed by the IED could be divided into three broad categories: "ambient

\footnotetext{
${ }^{37}$ Article 1 IED. For the concerns, see parts II, III.

${ }^{38}$ Lee (n3), 3.

${ }^{39}$ Article 4 IED.

${ }^{40}$ On the different meanings of 'integration', see Richard Macrory, 'Seminar on Industrial Emissions Control' LLM EU Environmental Law II 2011/2012.

${ }^{41}$ ibid and article 5(2) IED.

${ }^{42}$ Macrory (n 40).
} 
environmental quality"43 (or "target" ${ }^{\text {"44 }}$ ), "performance-based or output" and "specification or input" 46 standards. 'Target' standards, which "relate to the quality of the receiving medium" 47 , are explicitly provided for (in the form of $\mathrm{EQS}^{48}$ ) in article 18 IED. These EQS, which are traditionally set on a "single medium basis" 49 , appear rather incompatible with the "cross media pollution assessment" ${ }^{\text {"50 }}$ required by the principle of substantive integration. ${ }^{51}$ On the contrary, this principle is fully respected by the Directive's "emission- or performance-based standards". ${ }^{52}$ These take the form of $\mathrm{ELVs}^{53}$, which according to article 14(1) IED should have regard to the potential of their regulated substances "to transfer pollution from one medium to another". A significant feature of this type of standards is their flexible character. Whilst "prescribing levels of pollutants which may be discharged from an installation" ${ }^{34}$, 'emission-based standards' nevertheless allow, at least in principle, the operator to decide how best to meet the imposed conditions. ${ }^{55}$

Nonetheless, the Directive's third category of standards ('specification standards') appears to be the most significant in the promotion of substantive integration. Not only does the Directive's 'BAT' standard aspire to the same "environment as a whole analysis" standards'; it also and more importantly exhibits some of the key characteristics of the "lifecycle approach" 57 advocated by the 1991 OECD

\footnotetext{
${ }^{43}$ Joanne Scott, 'Flexibility in the Implementation of EC Environmental Law' (2000) Yearbook of European Environmental Law 41.

${ }^{44}$ Anthony I Ogus, 'Standard Setting for Environmental Protection: Principles and Processes' in Michael G Faure, John Vervaele and Albert Weale (eds) Environmental Standards in the European Union in an Interdisciplinary Framework (Blackstone 1994), 27.

45 ibid.

46 ibid.

${ }^{47}$ Macrory (n 1), 159.

${ }^{48}$ Environmental Quality Standards (EQS).

${ }^{49}$ ibid. EQS are included for instance in the Water Framework Directive (Directive 2000/60/EC establishing a framework for Community action in the field of water policy [2000] OJ L327/1) (WFD).

${ }_{51}^{50}$ Macrory (n 40).

${ }^{51}$ Lee (n 3).

${ }^{52}$ Lubbe-Wolf, (n 20).

${ }^{53}$ Emission Limit Values (ELVs).

${ }^{54}$ Macrory (n 1).

${ }^{55}$ Lubbe-Wolf (n 20).

${ }^{56}$ Article 1(10) IED.

${ }^{57}$ MJ Nicholas et al, 'Determination of 'Best Available Techniques' for Integrated Pollution Prevention and Control: A Life Cycle Approach’ (2000) 78: B3 Process Safety and Environmental Protection 193.
} 
Environmental Monograph. ${ }^{58}$ Accordingly, Annex III IED (which lists the criteria that need to be considered in the determination of 'BAT ${ }^{, 59}$ ) places particular emphasis on "low waste technology, energy efficiency and the recovery and recycling of waste". This allows, according to Macrory, the "wider integration of environmental concerns" $"$ in individual IPPC permits.

However, the significance of the 'BAT' standard is not solely related to its potential to promote an advanced form of substantive integration. Instead, as O'Malley contends, the 'BAT' standard provides "the principle benchmark for determining the obligations of industrial operators in respect of pollution prevention and control". ${ }^{61}$ Therefore, irrespective of whether the permit conditions include ELVs ${ }^{62}$ or "equivalent parameters or technical measures" ${ }^{\prime 3}$, these should always "be based on the best available techniques, without prescribing the use of any technique or specific technology". ${ }^{64}$ This last phrase is particularly important since it distinguishes the 'BAT' standard from the general category of 'specification standards'. Traditionally 'specification standards' have been perceived as prescribing "particular forms of technical solutions" had therefore been associated with regulatory rigidity and inefficiency. ${ }^{66}$ However, the 'BAT' standard appears to challenge this presumption. To begin with, article 3(10) IED, which contains the 'BAT' definition, coupled with the aforementioned Annex III IED, would appear to endow the 'BAT' standard with considerable prescriptive value. However its in-depth review appears to challenge this initial understanding. Subsequently, 'best' is contingent upon the technique's potential to achieve "a high general level of protection of the environment as a whole" ${ }^{67}$ Since the Directive does not define the level of protection which needs to be achieved, the latter is informed by the totality of the European Union's environmental

\footnotetext{
${ }^{58}$ Macrory (n 40); OECD, Organisation for Economic Cooperatives and Development (1991) Integrated Pollution Prevention and Control. Environment Monograph No 37.

${ }^{59}$ Article 14(6) IED.

${ }^{60}$ Macrory (n 40).

${ }^{61}$ V O'Malley, 'The Integrated Pollution Prevention and Control IPPC Directive and its implications for the environment and industrial activities in Europe' (1999) 59 Sensors and Actuators B, 78.

62 The IED prioritises ELVs as a means of incorporating the 'BAT' standard in individual permits. See: Lubbe-Wolf (n 20).

${ }^{63}$ Article 14(2) IED.

${ }^{64}$ Article 15(2) IED.

${ }^{65}$ Macrory (n 1), 159.

${ }^{66}$ Lubbe-Wolf (n 20).

${ }^{67}$ Article 3(10) IED.
} 
legislation. ${ }^{68}$ Moreover, the 'availability' of a technique is assessed on the basis of a cost-benefit analysis (CBA). ${ }^{69}$ Importantly though, the Directive provides "no further detail on either which costs and advantages might be relevant or the appropriate response to these costs and advantages". ${ }^{70}$ Accordingly, the Commission in its interpretation of the 'BAT' concept, perceived this CBA as primarily mandating "an assessment of the estimated net costs of implementing a technique in relation to the environmental benefits achieved through its implementation". ${ }^{71}$ Nevertheless, bearing in mind the "highly speculative" 72 character of any assessment of environmental benefits as opposed to the more straightforward costs of environmental protection, the outcome of any such an analysis is far from clear. ${ }^{73}$ Finally, even the term 'techniques' appears to be phrased in rather abstract terms. According to the EEB, this refers not only to the installation's "hardware"74 ("the technology used" ") but also to its "software"76 ("the way in which the installation is designed...operated and decommissioned" ${ }^{\prime \prime 7}$ ). Even though the former is relatively easy to define (it includes such aspects as "filters and other end-of-pipe technologies" "78), the latter's broad character effectively renders any definition elusive. In light of the above, Lee righty argued that "whilst there is considerable detail in the Directive on BAT, that detail is rather open-ended" ${ }^{79}$ As such the 'BAT' standard provides, at least in principle, both Member States and individual operators with substantial flexibility in the determination of its content. ${ }^{80}$ And it is precisely this flexibility that rebuts the long-established presumption regarding the rigidity of 'specification standards'.

\section{THE DIRECTIVE'S PROCEDURAL ASPECTS}

\footnotetext{
${ }^{68}$ European Environmental Bureau (EEB), New Features under the Industrial Emissions Directive (2011) 4, available at http://www.eeb.org/index.cfm/activities/industryhealth/industrial-emissions/the-eebs-position/.

${ }^{69}$ Commission, On the Road to Sustainable Production, COM(2003) 354 final, 14.

${ }^{70}$ Lee (n 15), 167.

${ }^{71}$ Commission (n 69), 15.

${ }^{72}$ Ogus (n 44), 26.

${ }^{73}$ Lee (n 3), 7.

${ }^{74}$ EEB (n 68), 4.

${ }^{75}$ Article 1(10) IED.

${ }^{76}$ EEB (n 68), 4.

${ }^{77}$ Article 1(10) IED.

${ }^{78}$ EEB (n 68), 4.

${ }^{79}$ Lee (n 15), 167.

${ }^{80}$ ibid, 168.
} 
The academic debate generated by the adoption of the IED focused, inter alia, on the Directive's "proceduralising" ${ }^{\prime 81}$ character. Within the European Union's environmental edifice, 'proceduralisation' appears to play two different roles. ${ }^{82}$ On the one hand, the legislation's emphasis on procedure as opposed to detailed substantive standards provides Member States with the necessary flexibility in its implementation. On the other hand, 'proceduralisation' frequently operates to constrain this flexibility. Accordingly, the imposition of reporting obligations upon Member States under article 72 IED and the Directive's emphasis on public participation under article 24 IED, clearly illustrate this latter function of 'proceduralisation'. ${ }^{83}$ On the contrary, the IED's "norm generation" 84 process, the 'Sevilla process', appears to resonate more with the former, facilitative role of the concept. ${ }^{85}$

Notwithstanding the significant roles played under the IED by the aforementioned procedural aspects, the focus of this part will solely be on the 'Sevilla process'. To begin with, the original IPPCD made no reference either to this process or to its outcome; the 'BAT Reference documents ${ }^{86}$ (BREFs). Article 16(2) IPPCD simply mandated the Commission "to organise an exchange of information between Member States and the industries concerned on best available techniques". Nevertheless, this 'information exchange' rapidly "evolved beyond the terms of the legislation" 87 into a robust "forum for multi-level collaborative governance" $^{88}$, which closely resembles the Common Implementation Strategy ${ }^{89}$ (CIS) established under the Water Framework Directive ${ }^{90}$ (WFD).

\footnotetext{
${ }^{81}$ On 'proceduralising directives' see Lee (n 15), ch 6.

${ }^{82}$ William Howarth, 'Aspirations and Realities under the Water Framework Directive: Proceduralisation, Participation and Practicalities' (2009) 21:3 Journal of Environmental Law, 391.

${ }^{83}$ Lee (n 3).

84 ibid 6.

${ }^{85}$ See part II of this paper.

${ }^{86}$ According to article 3(11) IED: “BAT Reference Document' means a document, resulting from the exchange of information organised pursuant to Article 13, drawn up for defined activities and describing, in particular, applied techniques [...] and any emerging techniques, giving special consideration to the criteria listed in Annex III".

${ }^{87}$ Lee (n 3), 8.

${ }^{88}$ Jane Holder and Joanne Scott, 'Law and 'New' Environmental Governance in the European Union' [2004] p3, available at: http://wwwsa.ucl.ac.uk/laws/clge/docs/Scott\%20and\%20Holder.pdf.

${ }^{89}$ Strategic Document, Common Implementation Strategy for the Water Framework

Directive (2000/60/EC).

${ }^{90}$ Water Framework Directive (n 49).
} 
Similarly to the IPPCD, the WFD makes no mention to this Strategy, which was subsequently perceived as tentatively premised upon recital 14 of the WFD's preamble. ${ }^{91}$ Accordingly, the informal character of these processes meant that their outcome ('BREFs' under the 'Sevilla process' and "guidance documents" 92 under the CIS) was perceived as having a nonbinding character. ${ }^{93}$ It is important though to note, that the IED, radically changed the legal status of the 'BREFs'; a point which will be further analysed in part III.

Nonetheless, even prior to the adoption of the IED, which firmly entrenched both the 'Sevilla process' and its 'BREF documents' in the European Union's legislative framework, academics were keen to emphasise the significance of this process. Bearing in mind the open-ended character of the IED's 'BAT' standard and the difficulties associated with its determination, the 'Sevilla process' appears to play a crucial role in assisting Member States in the implementation of the IED. Indeed, by establishing the 'best available techniques' for different industrial sectors at the Union level, the Sevilla process' 'BREF documents' can substantially reinforce the Member States' efforts to determine BAT at the national level. ${ }^{94}$ In the same vein, Lee was keen to emphasise the potential of the 'Sevilla process' to operate as a mechanism of "institutional learning". ${ }^{95}$ By bringing together a variety of state and non-state actors, this process effectively facilitates the dissemination of "a large number of technical information on what is "best practice' in different countries". ${ }^{96}$ This is particularly significant since, as Emmott argues, "this (information) might otherwise be unavailable to regulators and industry in some Member States". ${ }^{97}$ In this context, the quality of implementation appears to be directly linked with the availability of information. Even though there is some truth in the argument that the Sevilla process' 'information reserve' will promote better implementation, this is far from straightforward. As will be subsequently discussed, there are

\footnotetext{
${ }^{91}$ Lee (n 24).

${ }^{92}$ Strategic Document (n 89), 2.

${ }^{93}$ Lee (n 24), 53.

${ }^{94}$ See part III below. Attention should be paid in particular to Lange's argument about the 'expectation of closure' created by the 'Sevilla process, in Bettina Lange, Implementing EU Pollution Control-Law and Integration (CUP 2008), ch 6.

${ }^{95}$ Lee (n 3), 20.

${ }^{96}$ Neil Emmott, 'IPPC and Beyond-Developing a Strategic Approach to Industry for European Environmental Policy' (1999) 1:1 Journal of Environmental Policy and Planning 77, 79.

${ }^{97}$ ibid.
} 
a number of factors that constrain the ability of Member States to take full advantage of the Sevilla process' learning edifice. ${ }^{98}$

Furthermore, within the Sevilla process' framework 'institutional learning' becomes entangled with the notions of "deliberation" 99 and "technological innovation". ${ }^{100}$ To begin with, Scott perceives this process as premised upon a deliberative ideal, which effectively "privileges critical reason, over power" 101 and is therefore capable of producing improved outcomes; in this case high quality 'BREFs' ${ }^{102}$ It is precisely this deliberative exercise that allows participants to learn from each other and to cooperate in the formulation of 'BREFs' that fosters technological innovation; thus allowing for instance the development of "cleaner production techniques". ${ }^{103}$ In light of the above, the Sevilla process' ability to operate as a "key driver for improved environmental performance in the European Union" ${ }^{104}$ clearly resonates with the Union's aspiration to demonstrate environmental leadership on the international plane. ${ }^{105}$

\section{PROCEDURE AND SUBSTANCE, FLEXIBILITY AND “LEGALISM"106}

The open-ended character of the Directive's core substantive standard-the 'BAT' standard-, the inherently flexible ELVs and the emphasis on procedure as a mechanism of determining the content of 'BAT', would appear to refute the argument that the IED is more centralised than its predecessor; the IPPCD. However, the interplay between the Directive's diverse regulatory standards, the ability of 'procedure' to constrain flexibility and most importantly the enhanced legal status of the 'BAT' standard under the IED, appear to align the Directive with concepts of

\footnotetext{
${ }^{98}$ Charalambos Koutalakis et.al. 'When Soft Regulation is not enough: the Integrated Pollution Prevention and Control Directive of the European Union' (2010) Regulation \& Governance 4, 329.

${ }^{99} \mathrm{Scott}(\mathrm{n} 43), 58$.

${ }^{100}$ Gislev, (n 18) 1.

${ }^{101} \operatorname{Scott}(\mathrm{n} 43), 59$.

${ }^{102}$ On the importance of deliberation for the achievement of 'better solutions', see Jenny Steele, 'Participation and Deliberation in Environmental Law: Exploring a Problemsolving Approach' (2001) 21 (3) Oxford Journal of Legal Studies 415.

${ }^{103}$ O’Malley (n 61), 80.

${ }^{104}$ Commission (n 69), 16.

105 The European Union's desire to demonstrate environmental leadership is particularly evident in the field of climate change. The 'Climate and Energy Package' (2008) was clearly underpinned by this rationale.

${ }^{106}$ Lee (n 3), 3
} 
"legalism or interventionist regulation". 107 This juxtaposition of characteristics belonging to different governance models (decentralised and centralised respectively) already existed in the IPPCD. The fact that the IED largely replicates the governance structure of its predecessor may indicate the Commission's faith in "new, old governance" 108 and "experimentalism". ${ }^{109}$ It may though equally indicate the Commission's inability to fully comprehend the issues that generated the 'implementation gap' in the first place.

\section{Part II: The 'Sevilla Process' Revisited}

\section{THE "IMPLEMENTATION DEFICIT" "110 OF THE IPPC DIRECTIVE}

The outcome of a protracted period of negotiations, the IED aimed principally at addressing the IPPC Directive's implementation deficit. ${ }^{11}$ Within this context the Member States' limited implementation of the IPPC Directive's 'BAT' standard, appeared to be a recurrent theme in all Commission's reports and communications. Accordingly, the Commission's most recent report on the IPPCD explicitly stated that "the main problem $[\ldots]$ is the low proportion of permits reflecting the implementation of BAT, as indicated in the relevant BAT reference documents (BREFs)". ${ }^{112}$ As it will be subsequently discussed, a simple deviation from the 'BREFs' did not suggest failure on behalf of the Member State to comply with its obligations under the Directive. ${ }^{113}$ However, the setting of permit conditions on the basis of an arbitrarily chosen standard meant that the Member State was in breach of its core obligation under the IPPCD; the obligation to set permit conditions solely on 'BAT'. 114

In light of the above, both the Commission and academics have attempted to identify the factors that account for this situation. To begin with, "the vague provisions on BAT" 115 and the "large degree of

${ }^{107}$ ibid.

${ }^{108}$ On 'new, old governance', see Scott, Trubek (n 11).

${ }^{109}$ On 'experimentalist governance' in the EU, see Lee (n 3) p3 and Charles F Sabel and Jonathan Zeitlin, 'Learning from Difference: The New Architecture of Experimentalist Governance in the EU' (2008) 14:3 European Law Journal, 271.

${ }^{110}$ On the 'implementation gap' in the European Union's environmental law see Lee (n 15 ,) ch 3.

${ }^{111}$ Commission (n 34).

${ }^{112}$ Commission (n 27), 4

${ }^{113}$ Lee (n 3), 14.

${ }^{114}$ Article 9(4) IPPCD.

${ }^{115}$ Commission (n 34), 9. 
flexibility" 116 afforded to Member States to deviate from BAT in the permitting process have been considered as the principle rationales for the limited implementation of the 'BAT' standard. Similarly, "the unclear role of the BREFs" 117 , their highly technical character and the fact that they were only published in English, meant that these documents were of limited value for a number of "weak" ${ }^{118}$-in terms of their capacities-Member States. ${ }^{119}$ In addition, concerns about the "unbalanced" 120 character of the "Sevilla process' and the predominantly political character of the debates taking place within its ambit, provided an additional explanation for the restricted use of 'BREFs' by individual Member States. ${ }^{121}$ As a result, the alleviation of the aforementioned implementation hurdles was promoted under the IED through a variety of measures. These could be broadly grouped under two categories. The first is comprised of measures aimed explicitly at addressing the concerns permeating the 'Sevilla process', whereas the second is focused on measures aimed at enhancing the legal status of 'BAT' under the Directive.

\section{THE STRUCTURE OF THE 'SEVILLA PROCESS'}

As Lee contends "in many respects, article 13 IED places the status quo on a legislative basis". ${ }^{122}$ Therefore, the decision to draw up, review or update a 'BREF document' rests with the Commission, which "should aim to update BAT reference documents not later than 8 years after the publication of the previous version". ${ }^{123}$ The expectation that the Commission will frequently review the 'BREF documents' clearly resonates with the evolving character of the 'BAT' standard. ${ }^{124}$ Moreover, 'Technical Working Groups' (TWGs) consisting of "Member States, the industries concerned, non-governmental organisations promoting environmental protection and the Commission"125,

\footnotetext{
116 ibid.

117 ibid.

${ }^{118}$ On a discussion about 'weak states' and their implementation hurdles, see Koutalakis et al (n 98).

${ }^{119}$ Farmer (n 35) 271.

${ }^{120}$ Neil Emmott et al, 'Policy Review: IPPC and the Sevilla Process' (2007) 10:4 Environmental Policy and Governance 204, 205.

${ }^{121}$ Bettina Lange, 'Searching for the Best Available Techniques - Open and Closed Norms in the Implementation of the EU Directive on Integrated Pollution Prevention and Control' (2006) 2 International Journal of Law in Context 67.

${ }^{122}$ Lee (n 3), 8.

${ }^{123}$ Article 13(1) IED, Preamble recital 10 IED.

${ }^{124}$ Lee (n 3), 20.

${ }^{125}$ Article 13(1) IED.
} 
continue to represent the technical limp of the process, as opposed to the Forum, which represents the political one. ${ }^{126}$ Under the IED, the composition of these TWGs is defined by the Forum. ${ }^{127}$ This effectively circumscribes the right of environmental interest groups and industry to participate in BREF drafting, since they now have to be directly nominated by the Forum. In the same vein, a significant development under the new Directive was the "institutionalisation of the practice of the (IPPC Directive's) information exchange forum (IEF)" 128 through the establishment of the Forum. Accordingly the Forum is comprised of "representatives of Member States, international organisations representing the industries concerned and environmental interest groups which have an acceptable degree of European representation". ${ }^{129}$ Given that the choice of participants greatly impacts upon the final outcome of the process, the delineation of the Forum's membership could indeed have far-reaching implications. Even more so since according to article 13, the Forum is expected to provide its opinion on a variety of matters, including the highly significant "content of the BAT reference documents". ${ }^{130}$ Nevertheless, one of the key changes brought about by the IED was the introduction in the 'Sevilla process' of a second political-tier; a comitology committee. ${ }^{131}$ According to article 13(5) IED "decisions on the BAT conclusions shall be adopted in accordance with the regulatory procedure referred to in Article 75(2)". Whereas according to article 3(12) IED "BAT conclusions" are defined as "a document containing the parts of a BAT reference document laying down the conclusions on best available techniques". The significance of these provisions will become evident from the ensuing discussion.

\section{THE UNBALANCED 'SEVILLA PROCESS'}

Ever since its inception, the 'Sevilla process' was perceived as a deliberative framework within which, both state and non-state actors, would participate on equal footing in the determination of sectoral 'BATs'. However Lange's empirical account of the process clearly challenges this initial perception. ${ }^{132}$

\footnotetext{
${ }^{126}$ Lange (n 121), 77. Empirical evidence appear however to challenge this distinction.

${ }^{127}$ Commission Implementing Decision 2012/119/EU [2012] OJ L 63/1, Annex 4.4.1,

${ }^{128}$ EEB (n 68), 11.

${ }^{129}$ Commission Decision establishing a forum for the exchange of information pursuant to Article 13 of the Directive 2010/75/EU on industrial emissions, article 4-emphasis added.

${ }^{130}$ Article 13(4) IED.

${ }^{131}$ Lee (n 3), 9.

${ }^{132}$ Lange (n 94).
} 
Within this context, the unbalanced character of the process has been emphatically underscored. This characterisation essentially criticises the fact that, within the Sevilla process' edifice industry holds a more prominent position than the other non-state actor of the process; NGOs. ${ }^{133}$ To begin with, it is important to note that the industry's robust participation in the 'Sevilla process' is not inherently problematic. Both Lee and Don Litten highlighted the advantages of such a situation for all the involved parties. ${ }^{134}$ For instance, Lee perceived this as an opportunity for the other participants "to learn from and to use the information resources of industry"135 in the determination of the "dynamic BAT standard" ${ }^{136}$ Notwithstanding these arguments, it would appear that it is precisely this "informational asymmetry" 137 between the different actors that turns industry's prominence into 'unsettling' dominance. Even though under the 'Sevilla process' "the most comprehensive information usually originates from industry"138, the quality of this information is far from guaranteed. According to the Commission "economic data are frequently not made available, and when they are, it is usually not possible to cross-check them with data from other sources". ${ }^{139}$ Bearing in mind the centrality of the 'cost-benefits analysis' for 'BAT' determinations, the lack or even poor quality of available economic data appears particularly problematic. Consequently "industry's control over information" 140 and a number of arguments against its disclosure resulted in serious concerns about the reliability of the 'Sevilla process' being raised.

The employment of mechanisms aimed at enhancing the transparency of the process was therefore considered as an appropriate response to these concerns. The publication in 2006 of the horizontal "BREF on economics and cross-media effects" ${ }^{141}$ was perceived as a step towards the right direction. Indeed as stated in the document the key purpose of its

\footnotetext{
${ }^{133}$ Lee (n 3), 10.

${ }^{134}$ Lee (n 3) and Don Litten, 'The Sevilla Process' in Commission, On the Road to Sustainable Production in the Enlarged EU Integrated Pollution Prevention and Control (IPPC), Conference Proceedings, Dresden, 20-22 September 2005, available at http://www.yumpu.com/en/document/view/6322495/on-the-road-to-sustainableproduction-in-the-enlarged-eu.

${ }^{135}$ Lee (n 3), 21.

136 ibid 22.

${ }^{137}$ Lange (n 121), 83.

${ }^{138}$ Commission (n 69), 17.

139 ibid.

${ }^{140}$ Lange (n 121), 83.

${ }^{141}$ Commission, BREF on Economics and Cross-Media Effects (July 2006), available at: http://eippcb.jrc.ec.europa.eu/reference/BREF/ecm bref_0706.pdf.
} 
methodologies is to ensure "transparency so that any part of the process can be validated or audited". ${ }^{142}$ In this context, transparency does not only refer to the quality and availability of information that feeds into the process, but also and primarily to the way this information is treated by the participants of the process. This claim in favour of transparency could therefore be perceived as facilitating internal or "peer scrutiny". ${ }^{143}$ Here the role of NGOs appears particularly important. Their participation in the Sevilla process' institutions provides them with the opportunity to challenge the accuracy of the data provided both by industry and Member States and thus potentially operate as an informal pressure mechanism for the improvement of those actors' performance. ${ }^{144}$ However, the delineation of their participatory rights under the IED and the "resource intensive" 145 character of the "Sevilla process', mean that NGOs cannot always take full advantage of the aforementioned opportunity.

Moreover arguments in favour of transparency in the 'Sevilla process' are inextricably linked with mechanisms aimed at facilitating "external" public scrutiny of the process. The latter is predominantly promoted through the EIPPCB ${ }^{147}$, the website of which provides ample information on the 'Sevilla process' and its outcome; the 'BREFs'. Regrettably though, information about the process' specific participants (for instance their names or at least their professional affiliation) is no longer made publicly available by the Bureau, due to database protection rules. ${ }^{148}$ Taking into account the pervasive discourse over "industry bias" 149 in 'BREF' writing, being able to identify the source of information that underpins this process, is "a bare minimum, even if not the full picture". ${ }^{150}$

In the same vein, this form of public scrutiny is further enhanced by the participatory mechanism of article 24 IED. According to Lange "BAT determinations are embedded in a multi-level governance system" " 151 with the final level being occupied by Member States' competent authorities,

\footnotetext{
${ }^{142}$ Ibid iii.

${ }^{143}$ Lee (n 3), 11.

${ }^{144}$ Non-governmental organisations (NGOs) have always participated in the 'Sevilla process'. However, the IED formalised their participation. See Lange (n 121) 85.

${ }^{145}$ Lee (n 3), 11.

146 ibid.

${ }^{147}$ Commission, (n 127). The European IPPC Bureau coordinates the 'Sevilla process'.

${ }^{148}$ Lee (n 3), 10.

${ }^{149}$ EEB (n 68), 9.

${ }^{150}$ ibid.

${ }^{151}$ Lange (n 121), 81.
} 
which define "BAT in IPPC licenses for specific sites". ${ }^{152}$ Subsequently the public's (civil society and NGOs) ability to participate in the individual Member States' "permit procedure" ${ }^{153}$, appears particularly important. Indeed information submitted at this stage may not only challenge the information that formed the basis of the 'BREF' process but also operate as a gap-filling mechanism in cases of 'information-deficits'. Accordingly, it is envisaged that competent authorities will use this information in order to justify, under article 14(4) IED, the imposition of permit conditions that are stricter than those contained in 'BAT conclusions'. And even though this provision opens-up the possibility for Member States to voice their concerns over the reliability of the 'BREF' process, its application will be most likely strongly opposed by industry. ${ }^{154}$ In addition, a number of academics have already highlighted the potential of participatory processes, in practice, to exclude (either directly or indirectly) specific segments of society; usually those that lack the necessary cognitive or particularly in the case of NGOs, financial resources. ${ }^{155}$ Unarguably, this situation questions the value of the IED's participatory processes.

Finally, the newly introduced comitology procedure would appear to provide a better response to concerns about the unbalanced character of the 'Sevilla process'. In contrast to the other political institution of the process, the Forum, the article 75 comitology committee is envisioned as sheltered from industry's influence. Within this "protected space"156, Member States are given "an additional opportunity to intervene during the adoption of the BAT conclusions". ${ }^{157}$ Nevertheless, the establishment of a comitology committee does not fully obliterate concerns about the Sevilla process' biased character. In this respect particular emphasis has been placed on comitology's own "legitimacy issues" 158 , which are principally related to its "isolation from public scrutiny and from the democratic control of Parliament". ${ }^{159}$ Even though the new comitology procedure provided the European Parliament (and the Council) with "the right of scrutiny"160, the implications of this right are not as far-reaching as they may initially seem.

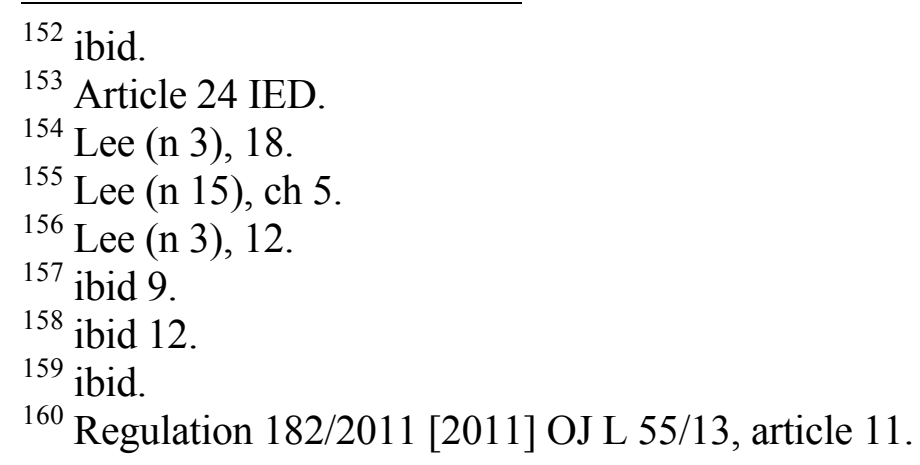


The European Parliament's power to check "whether implementing powers have been overstepped"161, means that the Parliament could use this power to scrutinize 'BAT' as defined in 'draft BAT conclusions' for conformity with its legislative definition under article 3(10) IED. Lee considers this as a significant opportunity for the Parliament to "flag political concerns in extremis". ${ }^{162}$ Although there is some truth in this argument, it is important to note that, under the comitology procedure, the decision whether to amend or withdraw the draft implementing act rests ultimately with the Commission. ${ }^{163}$ This clearly diminishes the importance of the European Parliament's contribution in practice.

The debate over the unbalanced character of the 'Sevilla process' has principally focused on the "power dynamics" 164 existing between industry and NGOs. However, Lange's account of the "North-South imbalances in BREF writing"165, elucidate another side of the problem. Accordingly, a claim that has been frequently advanced by the Sevilla process' participants was that "Northern European Countries were exerting too much influence upon BAT definitions". ${ }^{166}$ This influence could in some instances, as in the case of Germany and the Netherlands, be justified by the countries' considerable contributions-in terms of data and related information-in the process. ${ }^{167}$ Yet, in the majority of cases, "interest representation" ${ }^{168}$ rather than evidence-based argumentation underpinned State's attempts to steer the process towards a specific outcome. Within this context, states characterised by "weak economic, social and administrative conditions"169, lacked the necessary "regulatory and commercial power" in the process. This discrepancy in the 'bargaining power' of different Member States was also reflected on the produced 'BREFs'. The latter essentially crystallised "the state of BAT of advanced Northern and Western European industry". ${ }^{171}$

\footnotetext{
${ }^{161}$ Lee (n 3), 12.

162 ibid.

${ }^{163}$ Regulation 182/2011 (n 160) article 11.

${ }^{164}$ Lange (n 121), 83.

165 ibid 84.

166 ibid.

${ }^{167}$ EEB (n 68), 9.

${ }^{168}$ Lee (n 3), 9.

${ }^{169}$ Koutalakis et al (n 98), 335.

${ }^{170}$ Lange (n 94) 154.

${ }^{171}$ Koutalakis et al (n 98), 338.
} 


\section{THE POLITICAL CHARACTER OF A TECHNICAL DISCOURSE}

Decision-making under the 'Sevilla process' was originally envisaged as premised upon two strictly delineated discourses; a "technical discourse" 172 taking place within expert-led TWGs and a political discourse confined in what was formerly known as the IEF. ${ }^{173}$ However, empirical evidence appeared to challenge this perception. In particular the incorporation of policy issues in the discussions of TWGs created concerns about the dominance of politics over science in 'BAT' determinations. ${ }^{174}$ To begin with, the convergence of technical and policy or value-based arguments is not inherently problematic. 'BAT' is by definition an open-ended, flexible standard and the choice of 'BAT' for a particular industrial sector presupposes a choice between the diverse environmental, economic and societal benefits of the available 'BAT' options. ${ }^{175}$ These value judgmentsthe choice for instance between a 'BAT' that results in ELVs, which contribute to global warming and another with ELVs, which contribute to water pollution-permeate both tiers (technical and political) of the Sevilla process. ${ }^{176}$ In the same vein, a purely technical discourse within the TWGs runs the risk of reducing "highly political choices" ${ }^{177}$, as the one previously mentioned, into mere technical calculations. ${ }^{178}$ On the other hand, simple negotiation over the outcome raises questions about the credibility of 'BREF documents'.

Nevertheless, it would appear that negotiation, "hard and soft bargaining" 179 and an effort to reconcile the diverse interests of various participants have frequently dominated the discussions of TWGs. On this account, "interests or preferences" $" 180$ could be perceived as only loosely connected with the value judgments inherent in 'BAT' determinations. Indeed a Member State's preference for a specific 'BAT' could be primarily driven by its desire to retain the status quo of its own industry and only to a lesser extent by general policy considerations. ${ }^{181}$ This clearly illustrates the

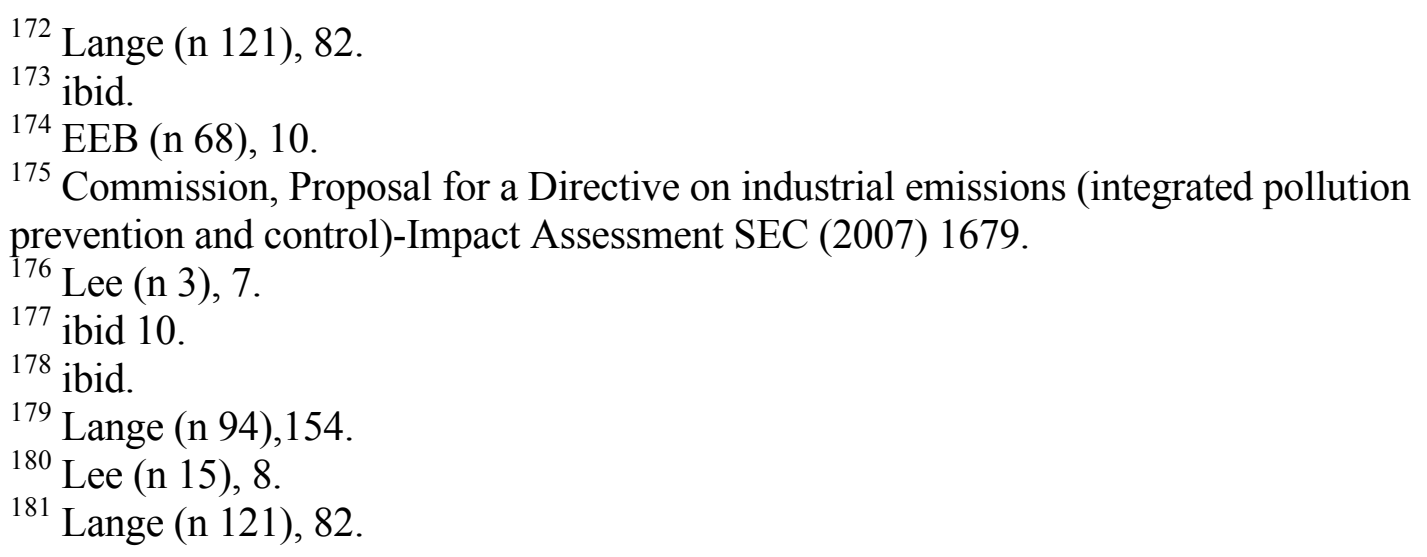


nebulous character of 'interests'. Within the 'Sevilla process' a watertight delineation between Member States as proponents of the public interest and industry representatives as advocates of private interests, appears untenable. ${ }^{182}$ Within this context, disclosure of information about the participants of the 'Sevilla process' becomes even more significant. Even more so, since the introduction of the comitology committee and the enhancement of the legal status of 'BREFs' under the IED, is bound to accentuate the political character of the TWGs' debates. ${ }^{183}$

\section{Part III: The enhanced Status of 'BAT Reference documents'}

\section{AN OVERVIEW}

One of the main concerns under the previous regime of the IPPCD was the limited application of the 'BAT' standard; a problem which was particularly observed in the weaker Member States of the European Union (mainly states situated in Southern and Eastern Europe). ${ }^{184}$ In order to address this situation, the IED adopted a number of measures, which principally aimed at enhancing the status of 'BAT' within national permitting systems. To begin with, for the first time a definition of the 'BREF documents' and 'BAT conclusions' is included in the Directive. ${ }^{185}$ The Directive also contains a definition of "emerging techniques" 186 , which are expected to form an integral part of the 'BREFs' under the new regime. This clearly illustrates the IED's unequivocal commitment to notions of "reflexivity" 187 and "learning". 188 'BAT' is an inherently 'dynamic concept' and the obligation imposed on the Sevilla process' participants to consider not only existing best available techniques, but also techniques that are most likely to "become BAT in the near future"189 clearly facilitates its constant evolution.

Nevertheless, the most important measure adopted by the Directive regarded the legal status of the 'BREF documents' and more specifically those parts of the documents that contained their conclusions on 'BAT' ${ }^{190} \mathrm{In}$ contrast to the previous regime, where 'BREFs' were just one of the factors

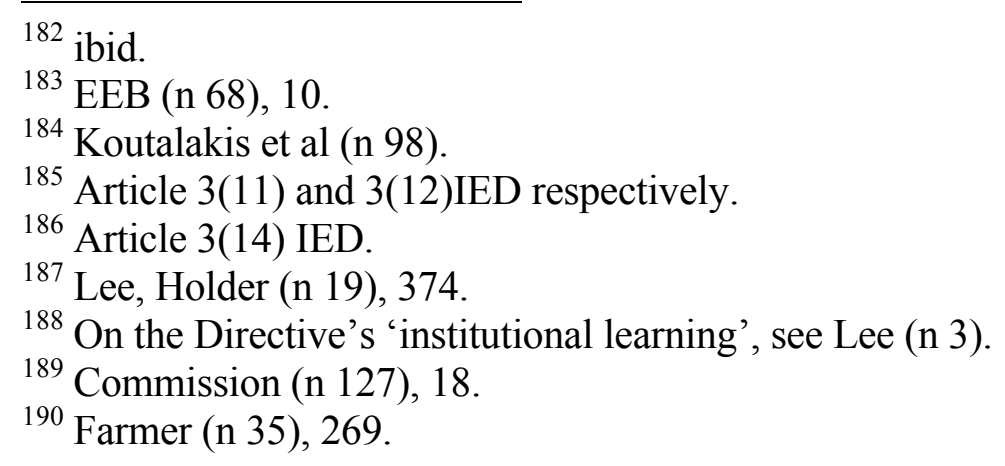


to be taken into consideration when determining 'BAT' in individual permits, 'BAT conclusions' are now "the reference for setting permit conditions". ${ }^{191}$ However this is not the end of the story. Interestingly, under the IED two categories of 'BAT conclusions' with different consequences co-exist. The first includes 'BAT conclusions' that have been formally adopted as implementing acts through a comitology decision. ${ }^{192}$ These are explicitly binding in terms of the ELVs prescribed in them. ${ }^{193}$ According to article 15(3) IED, "the competent authority shall set emission limit values that ensure that, under normal operating conditions, emissions do not exceed the emission levels associated with the best available techniques as laid down in the decisions on BAT conclusions referred to in Article 13(5)". Furthermore, the adoption of these conclusions through comitology has the effect of obliging the Commission to make them available in all the official languages of the Union. ${ }^{194}$ This appears to be a significant step towards the alleviation of some of the difficulties experienced by national authorities under the former regime. Finally, the existence of a comitology decision also impacts upon the competent authorities' obligation to regularly reconsider and update the permit conditions. ${ }^{195}$ According to article 21(3) IED, "within 4years of publication of decisions on BAT conclusions in accordance with Article $15(3)[\ldots]$ the competent authority shall ensure that all the permit conditions for the installation concerned are reconsidered and, if necessary, updated".

As far as the second category of 'BAT conclusions' is concerned, this is comprised of 'BREFs' that have either been published by the Commission before the adoption of the IED or that have not yet been adopted through comitology. ${ }^{196}$ In this case these 'BREF conclusions' "shall apply as BAT conclusions [...] except for Article 15(3) and (4)". ${ }^{197}$ Therefore even though they are not binding in terms of their ELVs, these 'BREFs' nevertheless have considerable "authority in the permitting process". ${ }^{198}$ In light of the above, the IED has been perceived as signifying a departure from the tenets of de-centralisation and flexibility embraced by the IPPCD. However, as it

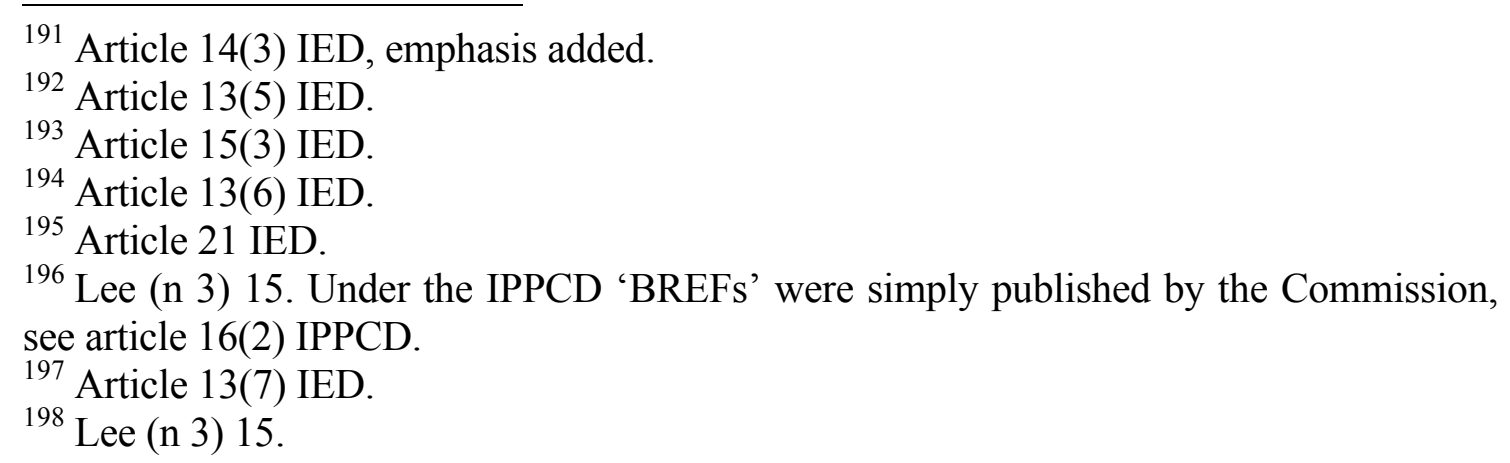


will be subsequently discussed, a closer assessment of the IED's regulatory edifice clearly rebuts this argument.

\section{BINDING 'BREFS' AND “OPEN BAT NORMS"199}

Bearing in mind the open ended character of the 'BAT' standard, it is not surprising that the 'Sevilla process' created "an expectation of closure" 200 "of whittling down a whole range of possible BAT candidates to one or few specific BAT techniques" ${ }^{201}$, which are subsequently incorporated into sectoral 'BREF' documents. Accordingly, it would appear that it was precisely this expectation of closure, which underpinned the Commission's decision to enhance the legal status of 'BREFs' under the IED. The assumption seems to be that the binding 'BAT conclusions' will simplify the implementation process for Member States; particularly for the weaker among them. ${ }^{202}$ However, as Lee contends "there is not always a simple read-across from BAT conclusions to permit conditions". ${ }^{203}$ In the same vein, Lange perceives the 'BAT' norms generated by the 'Sevilla process" "as situated on a sliding scale with various degrees of openness and closure" ${ }^{204}$ In their crudest form "closed norms" ${ }^{205}$ resemble "hard, state law" ${ }^{206}$, explicitly prescribing the BAT/BATs for a sector. ${ }^{207}$ On the contrary, "open norms" ${ }^{208}$ lack "prescriptive force" 209 as they fail to identify the BAT/BATs. ${ }^{210}$ Nevertheless, the existence of 'BAT' norms with varying degrees of openness is not inherently problematic or undesirable. Taking into account the differences between industrial installations, the 'open' character of 'BAT conclusions' provides competent authorities with the necessary flexibility for their accommodation. The 'BAT Conclusions on the iron and steel production" 211 , one of the first to be adopted under the IED,

\footnotetext{
${ }^{199}$ Lange (n 94) ch 6.

200 ibid 144.

201 ibid.

${ }^{202}$ Lee (n 3), 20.

203 ibid 19.

${ }^{204}$ Lange (n 94), 151.

205 ibid 148.

206 ibid 176.

207 ibid 148.

208 ibid 146.

${ }^{209}$ ibid.

210 ibid, emphasis added.

${ }^{211}$ Commission Implementing Decision 2012/135/EU [2012] OJ L 70/63 (BATC). The 'BAT Conclusions on manufacture of glass' were adopted at the same time as the BATC for the iron and steel production. More recently two more BATCs were adopted: the 'BAT Conclusions for the tanning of hides and skins (February 2013) and the 'BAT
} 
are instructive in this sense. Even though a number of techniques are listed as 'BAT' under the specific 'BATC', their applicability is nevertheless contingent upon a number of factors; including not only the "layout of the plant and space requirements" 212 but also the potential "high investment and operational costs". ${ }^{213}$ Moreover the ELVs associated with these techniques (BATAELs) are "expressed as ranges rather than as single values" 214 in order to "reflect the differences within a given type of installation (for instance differences in design, construction, size and capacity of the installation)". ${ }^{215}$

In light of the above, it becomes evident that "even with mandatory BAT conclusions, national regulators still have a crucial and difficult evaluative role". ${ }^{216}$ And although this is perfectly in line with the Directive's principle that "varied local conditions, require varied local environmental regulation" 217 , the concern about the inability of certain states and their competent authorities to successfully fulfil their aforementioned role remains. In addition, methodologies developed under the "BREF on economics and cross-media effects" ${ }^{218}$ to assist the Sevilla process' participants in their 'BAT' determinations, are of limited use at local level determinations. ${ }^{219}$ More importantly, even these methodologies do not absolve national authorities from difficult value judgments. As is explicitly stated in the pertinent 'BREF' "the methodology cannot make the decision, it is just a tool" ${ }^{\prime 220}$ aimed at assisting the actual decision-maker.

\section{3. “THE DEROGATION FROM BATAEL CLAUSE"221}

Whilst the introduction of a comitology procedure and the binding character of the 'BAT conclusions' adopted through it were perceived as facilitating a more consistent application of the 'BAT standard', the IED's derogation clause appeared to challenge this presumption. Article 15(4) IED allows competent authorities to set "less strict emission limit values" than those laid

Conclusions for cement, lime and magnesium oxide manufacturing industries' (April 2013).

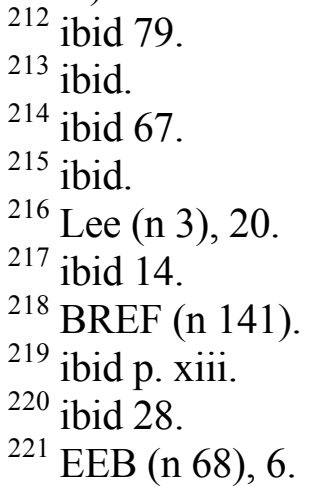


down in the binding 'BAT conclusions', provided that certain conditions are met. More specifically such derogation is only possible if the application of 'BAT conclusions' "would lead to disproportionately higher costs compared to the environmental benefits due to: (a) the geographical location or the local environmental conditions of the installation concerned; or (b) the technical characteristics of the installation concerned". To begin with, this derogation clause essentially crystallises the Directive's "ethos that divergent conditions may require divergent responses". 222 Bearing in mind the diversity of environmental conditions within different Member States, the IED, similarly to its predecessor, did not aim at "providing uniform substantive environmental standards". ${ }^{223}$ On the contrary it sought to establish a regulatory framework, which whilst being more hard-edged than the former (IPPCD), it still remains responsive to diverse circumstances. And while Lee acknowledged the significance of the IED's deference to local conditions, she nevertheless expressed concerns about the clause's potential to generate the same "implementation difficulties and divergence" 224 as the ones observed under the IPPCD. Indeed, not only is the cost-benefit analysis mandated by the derogation clause fraught with difficulties (as any CBA for that matter), but it is also couched in rather vague terms. ${ }^{225}$ For instance, the 'disproportionate' character of the costs leaves plenty of room for subjective interpretations.

Nevertheless, similarly to the IPPCD, the flexibility afforded to competent authorities under article 15(4) IED is woven in a framework of "substantive and procedural constraints". ${ }^{226}$ Accordingly, article 15(4) IED explicitly authorises the derogation from "BAT as described in BAT conclusions". It does not therefore sanction any derogation from the 'BAT' standard, the application of which remains mandatory even in the absence of specific 'BAT conclusions'. ${ }^{227}$ Moreover, the application of the derogation clause "without prejudice to article 18 " 228 illustrates the significant role played by 'ambient-based' standards under the Directive. Not only are competent authorities expected to set permit conditions that are stricter than those in 'BAT conclusions' in order to adhere to these $\mathrm{EQS}^{229}$; they are also

\footnotetext{
${ }^{222}$ Lee (n 3), 17.

${ }^{223}$ ibid 14.

${ }^{224} \mathrm{EEB}$ (n 68), 7.

${ }^{225}$ Lee (n 68), 17.

${ }^{226}$ ibid.

${ }^{227}$ Article 14(6) IED.

${ }^{228}$ Article 15(4) IED.

${ }^{229}$ Article 18 IED.
} 
obliged to comply with them even when they exercise their power under article 15(4) IED. The "European Safety Net"230, as currently crystallised in the "minimum EU-wide ELVs" ${ }^{231}$ contained in Annexes V-VII IED, represents a further limit to article's 18 IED derogation clause. Similarly, the obligation imposed upon competent authorities "to ensure that no significant pollution is caused and that a high level of protection of the environment as a whole is achieved" ${ }^{232}$ further constrains the flexibility provided by article 15(4) IED.

Furthermore, article 15(4) IED introduces a number of procedural constraints, which complement the aforementioned substantive ones. To begin with, even prior to the adoption of the IED, the Commission attached considerable importance to the then non-binding 'BREF' documents. In fact these 'BREFs' were "sometimes treated as quasi-legally binding"233 and there was an expectation that the imposition of more lenient conditions than those included in them would be "explicable in terms of BAT" ${ }^{234}$ More importantly this expectation was coupled with the potential of a challenge in front of the ECJ. ${ }^{235}$ It is precisely this expectation that was transformed into a legal obligation under article 15(4) IED. Accordingly, the competent authority is obliged to "document in an annex to the permit conditions the reasons for the application (of the derogation clause) including [...] the justification for the conditions imposed". Moreover, this "reason giving obligation" 236 is further enhanced by the second set of procedural constraints; the reporting obligations imposed upon Member States and the Commission by articles 72(1) and 73(1) IED respectively. According to the former Member States are expected to provide the Commission with information on, inter alia, "the application of best available techniques in accordance with articles 14 and 15 and in particular on the granting of exemptions in accordance with article 15(4)". ${ }^{237}$ Within the European Union's regulatory framework, the reports provided by Member States represent the main means through which the Commission exercises its role as "the guardian of the Treaties". ${ }^{238}$ To begin with, these reports could

\footnotetext{
${ }^{230} \operatorname{EEB}(\mathrm{n} 68), 13$.

${ }^{231}$ Lee (n 68), 24.

${ }^{232}$ Article 15(4) IED.

${ }^{233}$ Macrory (n 40).

${ }^{234}$ Lee (n 3), 14.

${ }^{235}$ Emmott et al (n 120), 205.

${ }^{236}$ Lee (n 3), 15.

${ }^{237}$ Article 72(1) IED.

${ }^{238}$ Lee, Holder (n 19), 403.
} 
potentially form the basis of infringement proceedings; for instance for nonapplication of the 'BAT' standard or for breach of article's 15(4) IED reason-giving obligation (e.g. non-existent or spurious justification). ${ }^{239}$ Furthermore, these reports could indicate the need for further clarification of article's 15(4) IED procedural and substantive criteria. ${ }^{240}$ The legal significance of any such clarification will be limited though, since the latter will be provided by the Commission through non-binding guidance. Finally according to article 73(1) IED, these national reports will form the basis of the Commission's periodic reports on the implementation of the IED. More importantly, this article imposes upon the Commission the obligation, within specific time-frame, "to assess the need for Union action through the establishment or updating of Union-wide minimum requirements for emission limit values" 241 and "where appropriate"242 to submit a legislative proposal. The EEB greeted this provision since it allows for the expansion of the currently rather weak 'European Safety $\mathrm{Net}^{243}$, with subsequent implications for article's 15(4) IED derogation clause. ${ }^{244}$ Even though there is some truth in the aforementioned arguments, the Commission's reliance on information provided either directly by Member States or through petitions and complaints, the poor quality of the reports and the fact that resort to the CJEU is only reserved for the most egregious cases, essentially dictate the way in which the Commission discharges its functions under the IED. ${ }^{245}$

A final procedural constraint is introduced by article 24 IED. According to the latter, both the decision to deviate from 'BAT conclusions' and the "specific reasons" 246 that support it, should be made available to the public. By supplementing the Commission's overview with this form of public scrutiny, the expectation seems to be that competent authorities will demonstrate considerable diligence in exercising their power under article

\footnotetext{
${ }^{239}$ Article 258 TFEU. On the obligation to provide reasons, see: Case C-75/08 The Queen on the application of C. Mellor v SoS for Local Government [2009] ECR I-03799. The case is concerned with the obligation to provide reasons under Directive 85/337/EEC (EIA Directive). Nevertheless para 66 of the judgment, which sets the criteria by which the sufficiency of the provided reasons is assessed, has wider significance.

${ }^{240}$ Article 15(4) IED.

${ }^{241}$ EEB (n68) 7.

${ }^{242}$ Article 73(1) IED.

243 ibid.

${ }^{244}$ EEB (n 68), 13.

${ }^{245} \mathrm{On}$ the issue of implementation of the EU's legislation, see: J. Jans, H. Vedder, European Environmental Law (2012) ch 4.

${ }^{246}$ Article 24 IED.
} 
15(4) IED; essentially that they will only abstain from the application of 'BAT conclusions' if they can "find, reflect on and disclose the reasons". ${ }^{247}$ This clearly indicates the "instrumental understanding" ${ }^{248}$ of public participation endorsed by the Directive. Within the Directive's edifice the public undertakes the significant role of policing its implementation on the ground. Nonetheless, as has already been implied, the extent to which the public will actually be able to play its envisaged role under the IED is highly debatable.

\section{E. CONCLUSION}

The cornerstone of the European Union's industrial pollution regulatory edifice, the IED was perceived as the answer to the IPPC Directive's "implementation gap". Premised upon the same principles as its predecessor, it established a permitting system aimed at achieving "a high level of protection of the environment taken as a whole". ${ }^{249}$ Even though the Directive appears, at least on the face of it, as capable of achieving its goal, a thorough assessment of its provisions critically challenges this perception. Indeed a number of concerns about the 'unbalanced' character of the 'Sevilla process' and the political character of the debates taking place in its TWGs, still remain in existence under the new regime. The role of the "BREF on economics and cross-media effects" ${ }^{250}$ in enhancing the transparency of the process is rather limited, as "even the most perfect methodology is no solution to poor data". ${ }^{251}$ Moreover the power of NGOs, as formal participants in the 'Sevilla process', to exercise internal or "peer scrutiny" 252 is equally constrained. And the same appears to hold true for the role of the public as facilitator of "external scrutiny". ${ }^{253}$ The potential of the new comitology committee to foster the transparency of the 'Sevilla process' is also questionable. In addition, it is expected that the former will accentuate the, already highly criticised, politicisation of the process.

In the same vein, academics have excessively questioned the extent to which the status of the 'BAT' standard is truly enhanced by the IED. Accordingly, debates over the more hard-edged, centralised character of the

\footnotetext{
${ }^{247}$ Lee (n 3), 18.

248 ibid 5.

${ }^{249}$ Lee (n 3), 12.

${ }^{250}$ ibid 11.

251 ibid.

${ }^{252}$ Scott (n 43).

${ }^{253}$ Macrory (n 40).
} 
IED have primarily focused on the binding status of the 'BAT conclusions'. However, the 'open' character of the 'BAT' norms contained in them, coupled with article's 15(4) IED derogation clause, appear to challenge this presumption. It is unarguably true that the IED aspires, as its predecessor, to a highly conditional flexibility. ${ }^{254}$ The existence of significant substantive and procedural constraints does not mean that flexibility does not exist. In fact even these constraints may not be as powerful as they may initially seem. Subsequently, the substantive conditions provide ample room for subjective assessments. And even though reporting obligations are understood as capable of imbuing national authorities with diligence in the exercise of their functions, this is far from straightforward.

In light of the above it could be concluded that the Directive's "learning curve" ${ }^{, 25}$ has yet to produce a straight line. Within the wider debate over the appropriate mode of environmental governance in the European Union, the Directive's adherence to 'new, old governance' raises serious concerns about its future.

\footnotetext{
${ }^{254}$ Scott (n 43).

${ }^{255}$ Macrory (n 40).
} 